\title{
Respostas da qualidade da água e fitoplânctons à redução de vazão e recepção de cargas de sedimentos no reservatório de Xingó/AL
}

\author{
Water quality and phytoplankton responses to flow \\ reduction and sediment load reception in the Xingó/AL \\ reservoir
}

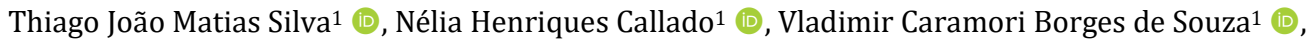
Maria Raphaella dos Santos Vasconcelos ${ }^{1}$ (D)

1Universidade Federal de Alagoas - UFAL, Maceió, AL, Brasil .E-mails: thiagomatias184@gmail.com, nelia.callado@yahoo.com.br,vcaramori@yahoo.com,maria.vasconcelos@ctec.ufal.br

\begin{abstract}
Como citar: Silva, T. J. M., Callado, N. H., Souza, V. C. B., \& Vasconcelos, M. R. S. (2020). Respostas da qualidade da água e fitoplânctons à redução de vazão e recepção de cargas de sedimentos no reservatório de Xingó/AL. Revista de Gestão de Água da América Latina, 17, e15. https://doi.org/10.21168/rega.v17e15
\end{abstract}

\begin{abstract}
RESUMO: No semiárido do nordeste brasileiro, o reservatório de Xingó é o último de um conjunto de reservatórios em cascata da bacia hidrográfica do rio São Francisco. Na perspectiva do fluxo das águas do rio, a acentuada redução das chuvas no ano de 2012 promoveu o programa de redução de vazão média a partir do ano de 2013, contextualizada pela seca mais severa dos últimos cem anos. Em 2015 foi dada uma descarga de fundo no reservatório de Delmiro Gouveia para o reservatório de Xingó, surgindo a preocupação sobre os efeitos dessas ações na qualidade da água desse reservatório. Dada a complexidade das variações da qualidade da água dos ecossistemas aquáticos, torna-se necessário ampliar o panorama das respostas físicas e químicas das águas de reservatórios inseridos em sistemas de cascatas. 0 presente artigo tem objetivo de avaliar os efeitos da redução de vazão do rio São Francisco (2013, 2014 e 2015) e da descarga de fundo (fev/2015) na qualidade da água e fitoplânctons do reservatório de Xingó no período de 2013 a 2016. Para tanto, foram levantados dados secundários hidrológicos e de qualidade da água disponibilizados pela ANA e CHESF. Três pontos de monitoramento da qualidade da água foram definidos, representando a parte anterior, intermediária e posterior. Os resultados mostraram que a redução de vazão aliada a descarga de sedimentos de montante levaram a alteração da concentração de nutrientes com consequente codominância de Ceratium furcoides e Cylindrospemopsis raciborskii.
\end{abstract}

Palavras-chave: Redução de Vazão; Descarga de Sedimento; Qualidade da Água; Reservatório de Xingó.

ABSTRACT: In the semi-arid region of northeastern Brazil, the Xingó reservoir is the last of a series of cascading reservoirs in the São Francisco river basin. From the perspective of river flow, the sharp reduction of rainfall in 2012 promoted the program of average flow reduction from 2013, contextualized by the most severe drought over the last hundred years. In 2015 a bottom discharge was given to the Delmiro Gouveia reservoir for the Xingó reservoir, raising concern about the effects of these actions on the water quality of this reservoir. Given the complexity of water quality variations in aquatic ecosystems, it is necessary to expand the panorama of physical and chemical responses of reservoir waters inserted in cascade systems. This article aims to evaluate the effects of the reduction in the flow of the São Francisco River (2013, 2014 and 2015) and the bottom discharge (Feb / 2015) on the water quality and phytoplankton of the Xingó reservoir in the period from 2013 to 2016 . For this purpose, secondary hydrological and water quality data were made available by ANA and CHESF. Three water quality monitoring points were defined, representing the front, middle and back. The results showed that the reduction of flow combined with the discharge of sediments upstream led to a change in the concentration of nutrients with consequent codominance of Ceratium furcoides and Cylindrospemopsis raciborskii.

Keywords: Flow Reduction; Sediment Flushing; Water Quality; Xingó Reservoir.

Recebido: Março 26, 2020. Revisado: Junho 21, 2020. Aceito: Setembro 02, 2020. 


\section{INTRODUÇÃO}

A qualidade da água do reservatório de Xingó é analisada sob a perspectiva da interferência da extrema redução de vazão do rio São Francisco e sob a ótica da interferência da recepção da descarga de sedimentos do reservatório de montante. No período de 2010 a 2015 a bacia do rio São Francisco enfrentou a maior seca dos últimos cem anos, como resposta a seca extrema, o programa de redução de vazão do rio São Francisco foi criado em 2013.

Nas extremas reduções de vazões, o registro científico da qualidade da água é importante para a compreensão dos ecossistemas hídricos e pode ser útil no enfrentamento de futuras vazões críticas no mundo, sobremaneira, no semiárido brasileiro (Mosley, 2015; Jones \& Van Vliet, 2018). Li et al. (2018) citam que em sistemas de reservatórios em cascatas, a compreensão dos efeitos da redução de vazão na dinâmica da qualidade da água, ainda é uma lacuna na literatura técnica e acadêmica.

Segundo Chiogna et al. (2018), na Itália, as águas dos reservatórios da bacia de Adige mostraram resiliência à redução de vazão no ano seco de 2017, no entanto, as águas de algumas regiões da bacia foram mais sensíveis ao estresse hídrico, apresentando elevação da condutividade elétrica e concentração de íons sódio.

Em contraste, em secas prolongadas como a estiagem de 2011 a 2015 nos rios do Sul dos Estados Unidos, a relação entre a condutividade e o índice de severidade de seca foi significativa, indicando que quanto maior o índice de severidade, maior a condutividade do rio, por consequência em diversos ambientes dessa bacia o aumento da condutividade restringiu a disponibilidade dos recursos hídricos para o abastecimento público (Jones \& Van Vliet, 2018).

Li et al. (2018) comentam que as águas dos lagos Lower Lakes, no semiárido da Austrália, apresentaram deterioração hídrica durante e após a redução de vazão, contudo a degradação foi mais acentuada na vazão reduzida, mostrando baixa eutrofização na região sudeste, moderada eutrofização na região nordeste e alto grau de trofia no noroeste.

Na região do semiárido brasileiro, nos reservatórios de Dourado e Cruzeta, durante a estiagem de maio de 2011 a dezembro de 2012, a redução do volume foi responsável por diminuição da transparência, aumento da turbidez e condutividade. No entanto, a redução do volume só foi associada com o aumento da concentração da clorofila a no reservatório de Dourado, indicando que o aumento da turbidez inorgânica, no reservatório de Cruzeta, foi o impedimento para o crescimento excessivo do fitoplâncton (Braga et al., 2015).

Na bacia do rio São Francisco, a redução de vazão foi responsável pelo aumento da salinidade em sua foz (Agência Nacional de Águas, 2019), interrompendo o abastecimento público por diversas vezes na cidade de Piaçabuçu/AL. Segundo Martins et al. (2019) a extrema redução de vazão afetou o balanço hídrico de Sobradinho com aumento da temperatura e taxas de evaporação, nessa mesma lógica, a redução do fluxo das águas alterou a dinâmica dos sedimentos, promovendo a degradação das águas na regiões médias e superiores. Esse autor cita que a escassez das águas no reservatório de Sobradinho se agrava na região do semiárido brasileiro, porque os reservatórios a jusante, como Paulo Afonso e Xingó, são dependentes da vazão sazonal de Sobradinho.

Em relação à descarga de fundo, o reservatório Delmiro Gouveia não efetivava tal operação há aproximadamente uma década, visto que a falta de manutenção no sistema de drenagem comprometia esse controle operacional (Instituto Brasileiro do Meio Ambiente e dos Recursos Naturais Renováveis, 2015). Por consequência, os sedimentos se acumularam, sendo transferidos para o reservatório de Xingó durante a descarga total de sedimentos ocorrida em fev/2015.

A descarga de sedimentos é uma prática saudável tanto para a vida do reservatório, quanto para o equilíbrio do ecossistema a jusante. No entanto, se tal operação é mal executada, causa efeitos nocivos ao meio ambiente. Assim se orienta a análise da quantidade e qualidade dos sedimentos, dragagem dos sólidos, em caso de toxicidade, e também a estimativa dos riscos ambientais tanto no reservatório, quanto no corpo receptor. Operacionalmente, recomenda-se, em batelada, uma descarga anual e em épocas de cheias (Baoligao et al., 2016).

Sob a perspectiva da dinâmica da descarga de sedimentos em rios e reservatórios, as areias e siltes recém-depositados se acomodam nos primeiros quilômetros, alterando a topografia com a criação de bancos de sólidos. Mesmo quando o lançamento de sedimentos é feito em pequenas proporções os efeitos podem ter repercussão durante décadas nos sistemas fluviais, topografia e nas estruturas de habitats em rios, reservatórios e canais de inundação (East et al., 2015).

Os efeitos negativos nos ecossistemas aquáticos são as alterações tanto imediatas quanto de longo prazo. Na qualidade da água, as mudanças em curto prazo são conhecidas, enquanto as transformações de longo prazo ainda necessitam ser compreendidas. Logo após a descarga de sedimentos, a literatura (Baoligao et al., 2016; Frémion et al., 2016; Peter et al., 2014) cita que o 
aumento dos sólidos suspensos se associa com o decréscimo do oxigênio dissolvido, tal como se relaciona com o aumento da turbidez, carbono orgânico dissolvido, nitrogênio amoniacal, nutrientes e metais.

Na perspectiva das consequências na vida aquática, Doretto et al. (2019) e Peter et al. (2014) verificaram que, após a descarga de fundo, houve, por mais de um ano, a diminuição da riqueza e alteração da estrutura e composição dos macroinvertebrados bentônicos. Na dinâmica do fitoplâncton, as consequências da descarga de sedimentos, ainda é uma lacuna.

Diante do exposto, o presente artigo tem o objetivo de compreender as consequências da sucessiva redução de vazão média $(2013,2014$ e 2015) da bacia do rio São Francisco na qualidade da água do reservatório de Xingó, bem como, busca-se entender as respostas da dinâmica ecológica do fitoplâncton nos dois eventos ambientais simultâneos, extrema redução de vazão e recepção da carga total dos sedimentos do reservatório Delmiro Gouveia em fev/2015.

\section{MATERIAIS E MÉTODOS}

\section{Área de estudo - Reservatório de Xingó}

A bacia hidrográfica do rio São Francisco (Figura 1) situa-se próximo à costa Atlântica, tem uma área de drenagem de $609.386 \mathrm{~km}^{2}$, seu rio principal, o São Francisco, tem extensão de 3.200 km desde sua nascente na Serra da Canastra/MG até a sua foz em Piaçabuçu/AL e Brejo Grande/SE e 54\% da bacia se encontra dentro do semiárido brasileiro. Essa bacia tem 0,9\% do uso do solo ocupado por áreas urbanizadas, 19,9\% por pastagens e 56,9\% por estabelecimentos agropecuários (Comitê da Bacia Hidrográfica do Rio São Francisco, 2016).

O reservatório de Xingó (Figura 2) é o último do sistema de cascatas da bacia do rio São Francisco, segundo a Agência Nacional de Águas (2019), até alimentar a vazão de Xingó, as águas seguem o seguinte percurso dentro do sistema de reservatórios: Três Marias > Sobradinho > Itaparica > Complexo Hidroelétrico de Paulo Afonso (onde está o reservatório de Delmiro Gouveia) > Xingó.

A área de estudo é o reservatório Xingó, que foi construído no ano de 1993, localiza-se no semiárido do nordeste brasileiro, na região hidrográfica do baixo São Francisco, está confinado em um Cânion a jusante do complexo hidrelétrico de Paulo Afonso/BA entre os Estados de Alagoas (AL) e Sergipe (SE) (Companhia Hidrelétrica do São Francisco, 2016). Xingó tem área de $60 \mathrm{~km}^{2}$, comprimento de $60 \mathrm{~km}$, volume total de $3.800 \times 10^{6} \mathrm{~m}^{3}$, regime de vazão a fio d'água, tempo de residência de 22 dias, cota máxima de 141 m, profundidade média de 80 m (Santos Júnior et al., 2003) e profundidade máxima de 170 m (Comitê da Bacia Hidrográfica do Rio São Francisco, 2020). Segundo a Fundação Apolônio Salles de Desenvolvimento Educacional (2009, 2010, 2011a), a baixa variação da amplitude térmica $\left(1,15^{\circ} \mathrm{C}\right)$ do reservatório de Xingó indica que não ocorre estratificação térmica, por isso o reservatório de Xingó pode ser classificado como holomítico (TUNDISI e TUNDISI, 2016).

0 reservatório de Xingó é utilizado para abastecimento público, turismo, pesca, piscicultura, navegação, irrigação e diluição de efluentes tanto domésticos quanto industriais. Segundo a Fundação Apolônio Salles de Desenvolvimento Educacional (2011b), os despejos de efluentes domésticos e industriais, de 2008 a 2010, não causaram impactos ambientais pontualmente na cabeceira do reservatório.

\section{Levantamento de dados}

O desenvolvimento deste trabalho foi feito a partir de dados secundários disponibilizados pela CHESF (Companhia Hidroelétrica do São Francisco), no site do Instituto Brasileiro do Meio Ambiente e dos Recursos Naturais Renováveis (IBAMA). Foram levantados dados limnológicos referentes aos anos de 2008 a 2016, dentre as variáveis limnológicas, podem-se destacar a temperatura, condutividade, transparência, pH, oxigênio dissolvido, fósforo total e densidade algal.

\section{Dados pluviométricos}

Como a pluviometria de toda a bacia interfere na dinâmica de vazões dos reservatórios, utilizouse dados dos pluviômetros instalados no alto, médio, submédio e baixo São Francisco (Figura 1), com séries históricas diárias de chuvas de 2007 a 2015 consultadas no site oficial da Agência Nacional de Águas (2018). 


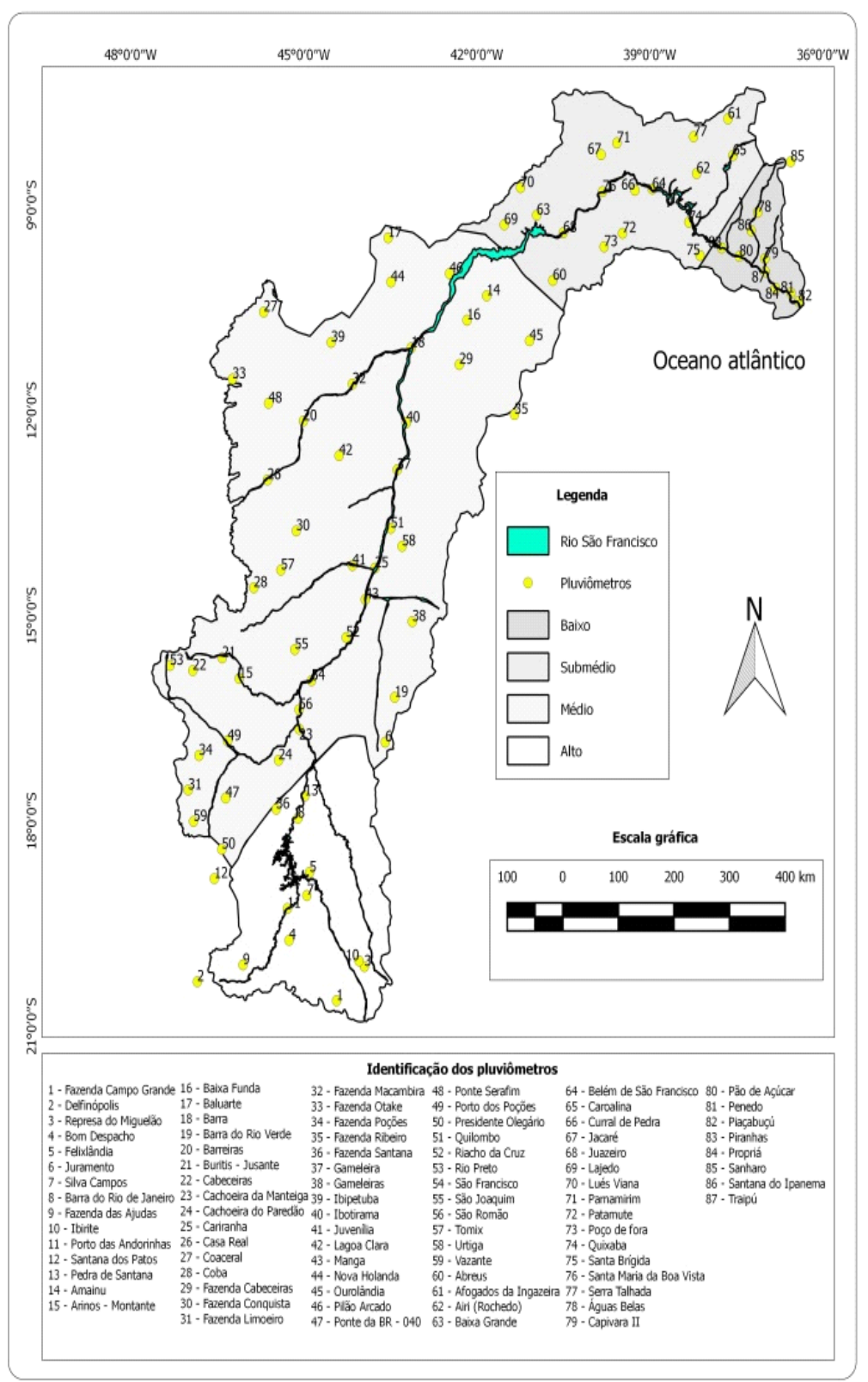

Figura 1 - Pluviômetros na bacia do rio São Francisco. Fonte: Sistema de Referência Geocéntrico para las Américas (2000), Instituto Brasileiro de Geografia e Estatística (2018). QGis 2.18.

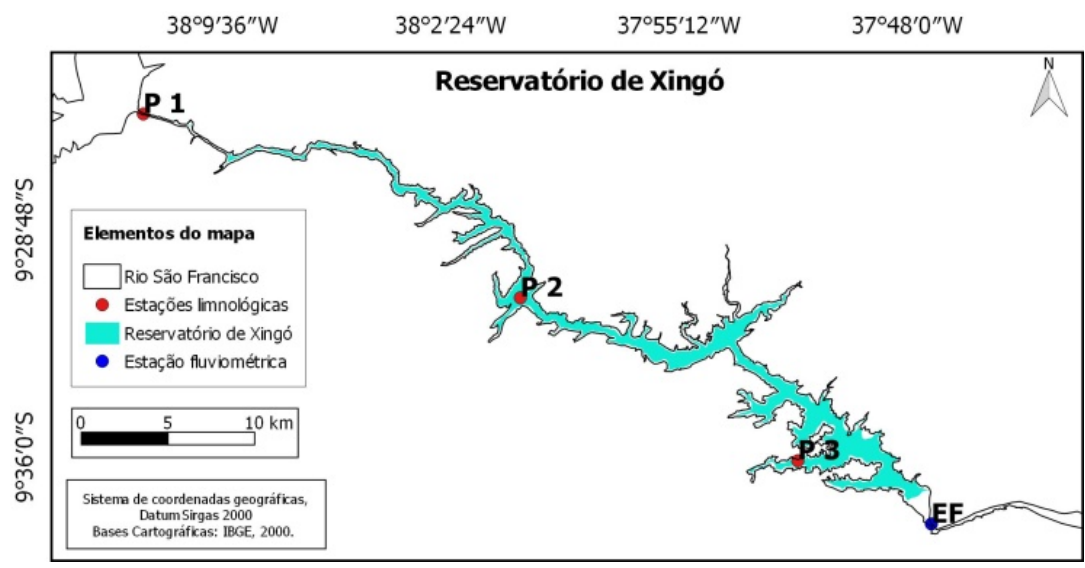

Figura 2 - Ilustração dos pontos de amostragem e localização da estação fluviométrica de Piranhas. Fonte: Sistema de Referência Geocéntrico para las Américas (2000), Instituto Brasileiro de Geografia e Estatística (2018). QGis 2.18 
A precipitação média anual das regiões hidrográficas e da bacia do rio São Francisco foram determinadas pelo método de Thiessen, considerando para isso os dados dos pluviômetros do alto, médio, submédio e baixo São Francisco e da bacia como um todo. Para identificar a variação pluviométrica na área de drenagem do reservatório de Xingó foi calculada a precipitação mensal utilizando a série histórica (1935 a 2018) das estações pluviométricas Delmiro Gouveia (00937013) e Piranhas (00937023), (Agência Nacional de Águas, 2018), localizadas no centro do reservatório e próximo à barragem de Xingó, respectivamente.

\section{Dados de Vazão}

O perfil temporal da vazão média e seu desvio padrão foram construídos com os dados diários da estação fluviométrica de Piranhas (Figura 2), no período de 2007 a 2015, tal estação tem código (ANA) 49330000 e localiza-se a jusante do reservatório de Xingó, em Piranhas/AL.

\section{Dados limnológicos de qualidade da água}

O levantamento de dados limnológicos foi feito por meio de parâmetros físico-químicos e da ecologia dos fitoplânctons, com coletas de água em três pontos no lago:

P1 - localizado a 6,0 km da usina hidrelétrica de Paulo Afonso IV, representativo da porção anterior do lago; P2 - localizado na calha central, representativo da parte intermediária do lago;

P3 - localizado na seção posterior, no ponto final de um meandro.

As amostras foram coletadas na superfície, a uma profundidade de aproximadamente $30 \mathrm{~cm}$, com o auxílio de uma garrafa de Van Dorn com capacidade de $5 \mathrm{~L}$, e em seguida acondicionadas em garrafas de polipropileno e refrigeradas em caixas isotérmicas, este monitoramento foi efetivado em três períodos distintos:

1) Anterior ao programa de redução de vazão, realizado trimestralmente sob responsabilidade da Fundação Apolônio Salles de Desenvolvimento Educacional (2009, 2010, 2011a), no período de dezembro de 2007 a setembro de 2010

2) Durante o programa de redução de vazão, realizado, mensalmente, sob responsabilidade da CHESF (Companhia Hidrelétrica do São Francisco, 2013, 2014, 2015), no período de junhodezembro/2013, janeiro/2014, abril/2014, setembro-dezembro/2014 e janeiro/2015.

3) Após a recepção da carga de sedimentos total do reservatório Delmiro Gouveia, realizado com a frequência mensal de fevereiro/2015 a março/2015, diária de abril/2015 a maio/2015 e quinzenal de julho/2015 a fevereiro/2016.

A Tabela 1 apresenta os parâmetros avaliados e suas respectivas metodologias.

Tabela 1 - Parâmetros e métodos de análise.

\begin{tabular}{c|c}
\hline \multicolumn{1}{c|}{ Análise } & Metodologia \\
\hline Temperatura & Sonda multiparâmetro YSI \\
\hline $\mathrm{pH}$ & Sonda multiparâmetro YSI \\
\hline Condutividade elétrica & Sonda multiparâmetro YSI \\
\hline OD & Sonda multiparâmetro YSI \\
\hline Transparência & Disco de Sechi (a sombra) \\
\hline Fósforo & Strickland \& Parsons (1960) \\
\hline Ecologia do fitoplâncton & Abundância relativa \\
\hline
\end{tabular}

Fonte: Fundação Apolônio Salles de Desenvolvimento Educacional (2009, 2010, 2011a), Companhia Hidrelétrica do São Francisco (2013, 2014, 2015).

\section{Estado de trofia}

O estado de trofia do reservatório de Xingó foi consultado nos relatórios técnicos da Companhia hidrelétrica do São Francisco do período de 2008 a 2010 (Fundação Apolônio Salles de Desenvolvimento Educacional, 2009, 2010, 2011a), cuja avaliação do estado trófico do reservatório foi baseada no índice de Estado trófico de Carlson (1977) e na ponderação proposta por Toledo 
Junior et al. (1983) ilustrada na Tabela 2, considerando os valores de transparência do disco de Secchi, clorofila-a e fósforo.

Tabela 2 - Ponderação do estado trófico.

\begin{tabular}{c|c}
\hline Análise & Metodologia \\
\hline Ultraoligotrófico & IET $\leq 24$ \\
\hline Oligotrófico & $24<$ IET $\leq 44$ \\
\hline Mesotrófico & $44<$ IET $\leq 54$ \\
\hline Eutrófico & $54<$ IET $\leq 74$ \\
\hline Hipereutrófico & IET $>74$ \\
\hline
\end{tabular}

Já o estado trófico do período da redução da vazão (2013 a jan/2015) e após a descarga de sedimentos (fev/2015 a fev/2016) foram efetivados conforme a mesma metodologia, no entanto, considerando no cálculo somente a concentração de fósforo total, como mostra a Equação 1.

$$
\text { IET }=10 \times\left[6-\left(\frac{\ln \left[\frac{80,32}{\mathrm{PT}}\right]}{\ln 2}\right)\right]
$$

\section{Ecologia do fitoplâncton}

As microalgas foram identificadas em microscópio invertido, analisando-se as suas características morfológicas e morfométricas, utilizando-se bibliografia especializada. Na Tabela 3, visualiza-se a metodologia e o laboratório responsável pela análise quantitativa, na vazão de referência (2007 a 2010) e após a recepção da carga de sedimentos (2015 e 2016).

Os dados quantitativos foram utilizados para o cálculo da abundância relativa, que foi realizado a partir da relação entre o número de cada táxon e o seu número total na amostra, o resultado foi expresso em porcentagem, sendo consideradas as categorias: dominante $(>70 \%)$, abundante $(\leq 70 \%$ e $>40 \%)$, pouco abundante $(\leq 40 \%$ e $>10 \%)$ e rara $(\leq 10 \%)$ (Tucci \& Sant'Anna, 2003). As espécies mais expressivas em termos quantitativos foram elencadas junto ao estado de trofia observado no reservatório.

Tabela 3 - Métodos da quantificação do fitoplâncton.

\begin{tabular}{|c|c|c|}
\hline Período & Metodologia & Laboratório \\
\hline $2007-2010$ & Utermõhl (Hasle, 1978) & UFRPE/PE UFAL/AL \\
\hline 2015 & $\begin{array}{c}\text { Sedwick-Rafter (American Public } \\
\text { Health Association, 2012) }\end{array}$ & Água e Terra/MG \\
\hline 2016 & Utermõhl (Hasle, 1978) & ECOTEC/SC \\
\hline
\end{tabular}

Fonte: Fundação Apolônio Salles de Desenvolvimento Educacional (2009, 2010, 2011a), Companhia Hidrelétrica do São Francisco $(2015,2016)$.

\section{Análise estatística}

Testa-se a hipótese que a redução de vazão média do rio São Francisco (2013 a 2015) somada à recepção da carga de sedimentos (fev/2015) foram responsáveis por mudanças nos padrões físicos, químicos e hidrobiológicos do reservatório de Xingó. Para avaliar tal afirmação o teste não paramétrico de Kruskal-Wallis foi efetivado, seguido do teste de comparações múltiplas de Dunn, comparando-se as variáveis físicas e químicas em três períodos distintos, vazão de referência (Qref: 2008 a 2010), vazão reduzida (Qred: jun/2013 a jan/2015) e após a recepção da carga de sedimentos (Rsed: fev/2015 a fev/2016).

Em P1 e P2, após a recepção de sedimentos (abr/2015 a fev/2016), o teste de Pearson foi aplicado para avaliar a correlação das variáveis físicas e químicas com a densidade de Ceratium furcoides, Cylindrospermopsis raciborskii e a total. 


\section{RESULTADOS E DISCUSSÃO}

\section{Análise pluviométrica - Reservatório de Xingó}

A Figura 3 apresenta a série histórica (1935 a 2018) da precipitação média mensal do reservatório de Xingó, o período de março a julho foi chuvoso, destacando-se a maior pluviosidade média mensal com 65,3 mm em março, enquanto que o período seco foi de agosto a dezembro, sendo a menor precipitação média mensal com 11,6 mm em outubro, já janeiro e fevereiro foram meses com chuvas intermediárias.

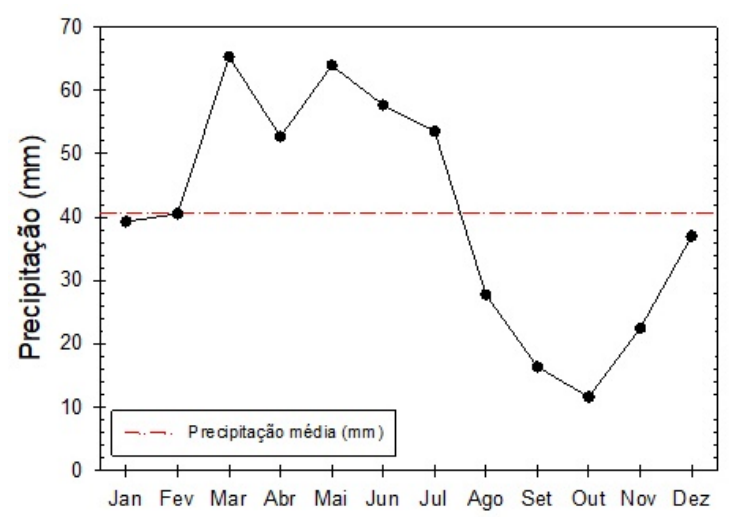

Figura 3 - Precipitação média mensal do reservatório de Xingó (1935 a 2018).

\section{Análise pluviométrica - Rio São Francisco}

Na Tabela 4, verificou-se que precipitação média anual da bacia nos anos de 2007 a 2011 foi de $946,9 \pm 141,81 \mathrm{~mm}$ e nos anos de 2012 a 2015 foi de $685,7 \pm 174,8 \mathrm{~mm}$, o que demonstra um déficit hídrico médio da ordem de 261,2 mm (27,6\%).

Tabela 4 - Precipitação média da bacia do São Francisco nos períodos de 2007 a 2011 e de 2012 a 2015.

\begin{tabular}{|c|c|c|c|c|c|c|}
\hline \multirow{2}{*}{ Período } & \multirow{2}{*}{ n-amostral } & \multicolumn{5}{|c|}{ Precipitação média anual \pm desvio padrão (mm) } \\
\hline & & Alto & Médio & Submédio & Baixo & Bacia \\
\hline 2007 a 2011 & 5 & $1.427,2 \pm 281,0$ & $947,6 \pm 133,0$ & $555,7 \pm 121,1$ & $851,2 \pm 86,1$ & $946,9 \pm 141,8$ \\
\hline 2012 a 2015 & 4 & $1.114,7 \pm 277,8$ & $707,5 \pm 196,4$ & $281,2 \pm 88,7$ & $523,2 \pm 138,1$ & $685,7 \pm 174,8$ \\
\hline
\end{tabular}

Para o período de estudo, 2007 a 2015, a precipitação média anual da bacia do São Francisco está ilustrada na Figura 4, discriminada por região do alto, médio, submédio e baixo São Francisco, assim como para a bacia como um todo. Jong et al. (2018) citam que, no período de 1961 a 1990, a precipitação média anual do rio São Francisco foi $1.083 \mathrm{~mm}$ e destacaram que a precipitação anual do século XX (1930 a 1990) só foi abaixo de $820 \mathrm{~mm}$ em um único ano.

Comparando a precipitação média da bacia de 2012 a $2015(685,7 \mathrm{~mm})$ com a média de longo prazo de $1.083 \mathrm{~mm}$ relatada por Jong et al. (2018), nota-se um déficit hídrico da ordem de 397,3 $\mathrm{mm}$ $(36,7 \%)$. Mas esses autores também comentam que a precipitação anual tem sido abaixo da média de longo prazo desde o ano de 1992.

Na série histórica de 2010 a 2015, o ano mais seco da bacia do rio São Francisco foi o ano de 2015 com a precipitação média de 563,4 mm, assim, a precipitação do ano de 2015 foi equivalente à metade (50\%) da precipitação média de longa duração (1.083 mm). Nesse contexto, Martins et al. (2019) destacam o ano de 2012 como o marco do início consecutivo de chuvas abaixo da média, tanto nas regiões hidrográficas, quanto na bacia do rio São Francisco, exceto em 2013. 


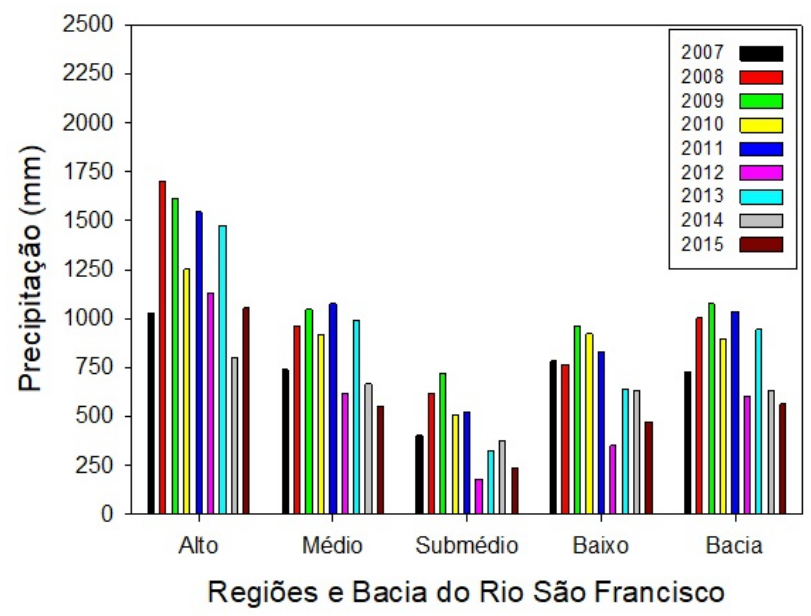

Figura 4 - Pluviometria média anual da bacia e das regiões do alto, médio, submédio e baixo São Francisco, de 2007 a 2015.

É possível observar na Figura 4 que a região do submédio é a que apresenta mais baixa pluviometria, haja vista a sua inserção no semiárido do Nordeste Brasileiro, tal região hidrográfica destaca-se por exercer fortes influências na qualidade da água do baixo São Francisco (Medeiros et al., 2016), onde se localiza o reservatório de Xingó. Como visto também nas outras regiões, é visível o déficit pluviométrico do ano de $2012(180,7 \mathrm{~mm})$ e os anos subsequentes com chuvas abaixo da média. Na Tabela 4, confrontando a pluviosidade média de 2007 a $2011(555,7 \pm 121 \mathrm{~mm})$ com a pluviosidade média de 2012 a $2015(281,2 \pm 88,7 \mathrm{~mm})$, nota-se um decaimento médio de 274,5 mm, representando um déficit de aproximadamente $50 \%$.

Já na região do alto e médio, a precipitação no período de 2007 a 2011 (Tabela 4) apresentou valor médio de 1427,2 $\pm 281,0 \mathrm{~mm}$ e $947,6 \pm 133,0 \mathrm{~mm}$, já no período seco de 2012 a 2015 a média foi de $1114,7 \pm 277,8 \mathrm{~mm}$ e 707,5 $\pm 196,4 \mathrm{~mm}$, assim, a diminuição média entre os dois períodos foi $312,5 \mathrm{~mm}$ e $240,1 \mathrm{~mm}$, respectivamente. A Agência Nacional de Águas (2019) cita que a precipitação da região hidrográfica do alto e médio é responsável por mais de 95\% da vazão do rio São Francisco, e que a redução da pluviosidade nessas regiões implica estresse hídrico nas regiões do submédio e baixo.

\section{Redução da vazão do reservatório de Xingó}

Os valores médios e o desvio padrão da vazão do reservatório de Xingó do período de 2007 a 2015 são apresentados na Figura 5, permitindo verificar nitidamente o decaimento da vazão média a partir do ano de 2013. A vazão média do período de 2007 a 2012 foi 2.005,6 $\pm 735,3 \mathrm{~m}^{3} / \mathrm{s}$, enquanto que a vazão média do período de 2013 a 2015 foi 1.105,8 $\pm 218,2 \mathrm{~m}^{3} / \mathrm{s}$. Já a vazão de longa duração (1961 a 1990) foi $2.895 \mathrm{~m}^{3} / \mathrm{s}$ (Jong et al., 2018).

0 déficit da vazão reduzida em relação à vazão de referência e a de longa duração foram respectivamente $899,8 \mathrm{~m}^{3} / \mathrm{s}(44,9 \%)$ e $1.789,2 \mathrm{~m}^{3} / \mathrm{s}(61,8 \%)$. Segundo Lehman et al. (2017), a redução de vazão implica o aumento do tempo de residência, certamente isso ocorreu no sistema de reservatórios do rio São Francisco.

A redução de vazão média do reservatório de Xingó foi gradual nos anos de 2013, 2014 e 2015, apresentando média de 1.296, 1.084 e $937 \mathrm{~m}^{3} / \mathrm{s}$, comparando-se esses valores com a média de longo prazo, $2.895 \mathrm{~m}^{3} / \mathrm{s}$ (Jong et al., 2018), respectivamente, houve um déficit de 1.599 (55,2\%), 1.811 $(62,6 \%)$ e $1.958(67,6 \%) \mathrm{m}^{3} / \mathrm{s}$.

Compreendendo que a diminuição da precipitação implica redução da vazão, então, é imprescindível estimar a magnitude dessa relação. Nesse sentido, Jong et al. (2018) estimaram o fator de elasticidade da vazão em função da precipitação a partir da série histórica do período 1980 a 2017, esse fator variou de 1,7 a 1,8; testando a aplicação desse coeficiente na redução de vazão de 2012 a 2015, observa-se que a precipitação foi 36,7\% menor que a média de longa duração (1.083 mm), enquanto que, no período de 2013 a 2015 , a vazão foi $61,8 \%\left(1.105,8 \mathrm{~m}^{3} / \mathrm{s}\right)$ menor que a média de longo prazo $\left(2.895 \mathrm{~m}^{3} / \mathrm{s}\right)$, isso corresponde a um fator de 1,7 , sendo assim, em estiagens prolongadas, a redução de $36,7 \%$ na precipitação da bacia do rio São Francisco pode reduzir a vazão média anual do reservatório de Xingó em mais de 60\%. 


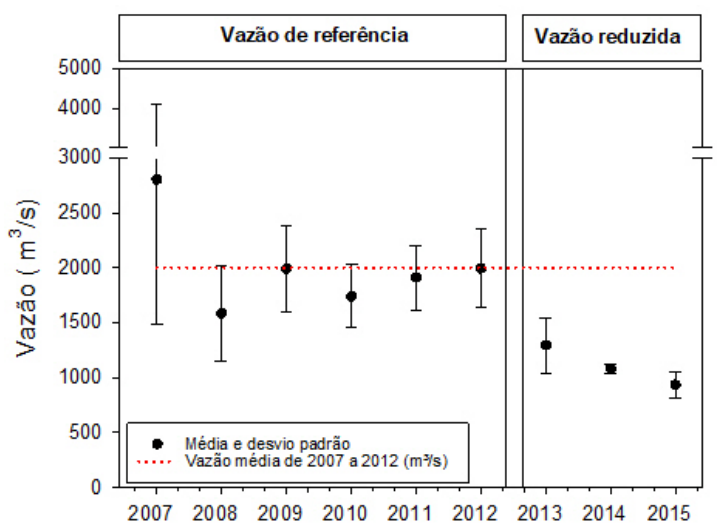

Figura 5 - Média e desvio padrão da vazão do reservatório de Xingó de 2007 a 2015.

\section{Qualidade da água}

A Tabela 5 mostra os resultados do teste de Kruskal-Wallis seguido do teste de Dunn, que foram utilizados para verificar se houve alteração na qualidade da água de cada estação (P1, P2 e P3) durante três eventos ambientais distintos, tais eventos foram vazão de referência-Qref (2008 a 2010), vazão reduzida-Qred (jun/2013 a jan/2015) e recepção de sedimentos-Rsed (fev/2015 a fev/2016).

Tabela 5 - Medianas e comparação da dispersão dos parâmetros físico-químicos estudados.

\begin{tabular}{|c|c|c|c|c|c|}
\hline \multicolumn{6}{|c|}{ Ponto 1} \\
\hline Variável & Qref & Qred & Rsed & $\mathbf{P}(\mathrm{KW})$ & Dunn $(\mathrm{P}<0,05)$ \\
\hline $\mathrm{n}$ amostral & 12 & 15 & 53 & & \\
\hline Temperatura $\left({ }^{\circ} \mathrm{C}\right)$ & 26,7 & 26,2 & 27,8 & $<0,001$ & Qref x Rsed / Qred x Rsed \\
\hline Condutividade $(\mu \mathrm{S} / \mathrm{cm})$ & 74,0 & 65,0 & 72,0 & $<0,001$ & Qref x Qred / Qred x Rsed \\
\hline Transparência (m) & 3,5 & 4,6 & 2,2 & 0,024 & Qred x Rsed \\
\hline $\mathrm{pH}$ & 7,8 & 7,6 & 8,4 & $<0,001$ & Qref x Rsed / Qred x Rsed \\
\hline $\begin{array}{l}\text { Oxigênio dissolvido } \\
\text { (mg/L) }\end{array}$ & 7,2 & 7,7 & 7,1 & 0,094 & \\
\hline Fósforo total $(\mu \mathrm{g} / \mathrm{L})$ & 45,0 & 33,5 & 42,4 & 0,483 & \\
\hline \multicolumn{6}{|c|}{ Ponto 2} \\
\hline Variável & Qref & Qred & Rsed & $\mathrm{P}(\mathrm{KW})$ & Dunn $(\mathrm{P}<0,05)$ \\
\hline $\mathrm{n}$ amostral & 12 & 15 & 49 & & \\
\hline Temperatura $\left({ }^{\circ} \mathrm{C}\right)$ & 27,5 & 27,8 & 28,4 & $<0,001$ & Qref x Rsed / Qred x Rsed \\
\hline Condutividade $(\mu \mathrm{S} / \mathrm{cm})$ & 74,0 & 67,0 & 71,7 & 0,003 & Qref x Qred / Qred x Rsed \\
\hline Transparência (m) & 4,5 & 3,6 & 2,6 & 0,004 & Qref x Rsed \\
\hline $\mathrm{pH}$ & 8,1 & 8,3 & 8,5 & 0,002 & Qref x Rsed \\
\hline $\begin{array}{l}\text { Oxigênio dissolvido } \\
\text { (mg/L) }\end{array}$ & 7,4 & 8,5 & 7,1 & $<0,001$ & Qref x Qred / Qred x Rsed \\
\hline Fósforo total $(\mu \mathrm{g} / \mathrm{L})$ & 50,0 & 28,3 & 36,0 & 0,312 & \\
\hline \multicolumn{6}{|c|}{ Ponto 3} \\
\hline Variável & Qref & Qred & Rsed & $\mathbf{P}(\mathrm{KW})$ & Dunn $(P<0,05)$ \\
\hline $\mathrm{n}$ amostral & 12 & 15 & 15 & & \\
\hline Temperatura $\left({ }^{\circ} \mathrm{C}\right)$ & 27,9 & 29,1 & 28,5 & 0,216 & \\
\hline Condutividade $(\mu \mathrm{S} / \mathrm{cm})$ & 80,0 & 69,0 & 75,0 & 0,029 & Qref x Qred \\
\hline Transparência (m) & 3,7 & 2,6 & 1,9 & 0,004 & Qref x Rsed \\
\hline $\mathrm{pH}$ & 7,7 & 8,4 & 7,8 & 0,005 & Qref x Qred \\
\hline $\begin{array}{c}\text { Oxigênio dissolvido } \\
(\mathrm{mg} / \mathrm{L})\end{array}$ & 6,3 & 8,5 & 7,7 & 0,002 & Qref x Qred \\
\hline Fósforo total $(\mu \mathrm{g} / \mathrm{L})$ & 50,0 & 67,0 & 66,0 & 0719 & \\
\hline
\end{tabular}


No sentido de ampliar a análise da qualidade da água, a Figura 6 apresenta o boxplot das variáveis físicas e químicas de P1, P2 e P3 na Qref, Qred e Rsed.
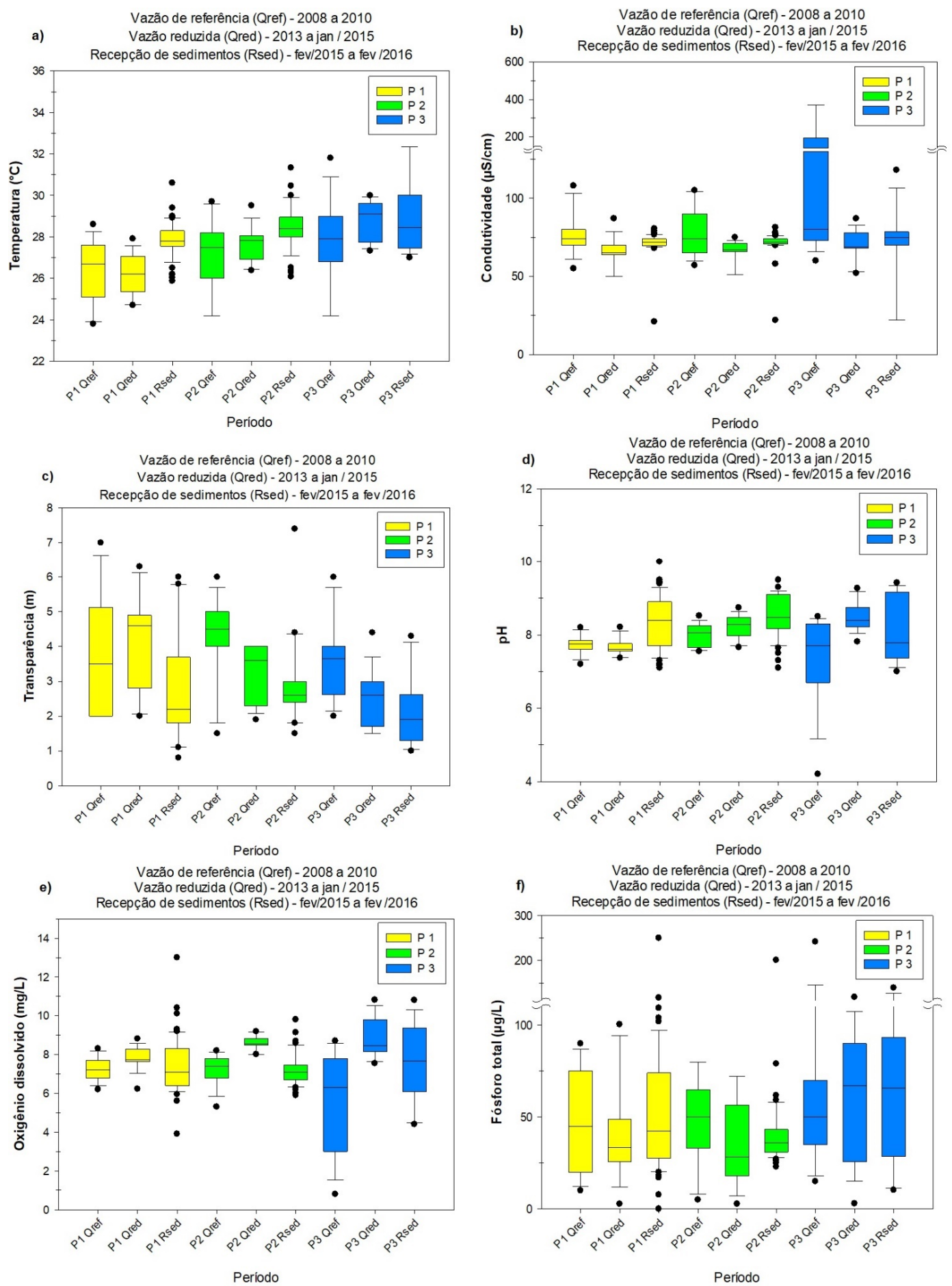

Figura 6 - Diagramas de caixas comparando os comportamentos das variáveis físicas e químicas de P1, P2 e P3, na vazão de referência, redução de vazão e após a recepção da carga de sedimentos.

\section{Temperatura}

Segundo a Fundação Apolônio Salles de Desenvolvimento Educacional (2009, 2010, 2011a), na Qref: 2008 a 2010, o reservatório de Xingó apresentou temperatura média de $27,6{ }^{\circ} \mathrm{C}$ em suas águas superficiais e amplitude térmica da coluna d'água de $1,2{ }^{\circ} \mathrm{C}$, assim, apontando para a ausência da estratificação térmica. 
A Figura 6a mostra os resultados das medições da temperatura a $30 \mathrm{~cm}$ de profundidade, pela análise da Figura 6a, percebe-se que a redução de vazão não alterou o valor da mediana e o padrão de distribuição em P1 e P2. Em P3 houve um acréscimo da mediana no valor de $1,2{ }^{\circ} \mathrm{C}$ e em relação à distribuição dos dados, o teste de Dunn (Tabela 5) indicou que houve homogeneidade $(\mathrm{P}>0,05)$ entre as variabilidades de Qref e Qred.

Com a descarga de sedimentos a temperatura de P1 e P2 sofreram mudanças em seus perfis de distribuição (Kruskal-Wallis, $\mathrm{P}<0,001$ ), diferindo dos dois períodos antecessores Qref e Qred (Dunn, $\mathrm{P}<0,05)$, nesse mesmo raciocínio, divergindo de P1 e P 2, o comportamento da temperatura de P3 praticamente não sofreu alteração (Figura 6a). Nota-se a resiliência em P3 (próximo à barragem) e a coincidência do local da descarga de sólidos (cabeceira) com o local de P1 (cabeceira) e P2 (centro), esses dois fatores agregam mais evidências para a confirmação que o lançamento de sedimentos do reservatório Delmiro Gouveia resultou no desequilíbrio térmico das seções anterior e intermediária do reservatório de Xingó.

Observou-se que, após algumas horas da descarga de fundo de reservatórios, ocorreu a elevação da temperatura em corpos de águas receptores (Baoligao et al., 2016; Chung et al., 2008), e esses efeitos também foram identificados em P1 e P2, no entanto, após alguns meses de tal operação. 0 mecanismo de aumento da temperatura, em virtude da descarga de sedimentos, ainda não é bem compreendido, porém, o acréscimo da temperatura coincidiu com a ressuspensão de sedimentos, indicando transferência de energia térmica no transporte de partículas sólidas e/ou perturbação térmica nesses ecossistemas aquáticos.

\section{Condutividade}

A redução da vazão, geralmente, eleva a condutividade das águas de reservatórios (Braga et al., 2015, Mosley et al., 2012) e rios (Jones \& Van Vliet, 2018), mesmo diante dessa situação, as águas de P1, P2 e P3 apresentaram redução da condutividade (Figura 6b). Segundo Medeiros et al. (2016), a condutividade do baixo São Francisco, região hidrográfica do reservatório de Xingó, sofre forte influência da precipitação da região do submédio, principalmente, das chuvas concentradas de janeiro e fevereiro, que lixiviam os íons dos solos salinos, transportando tais elementos químicos para o baixo São Francisco. Assim, a diminuição da condutividade do reservatório de Xingó é explicada, como visto, pela redução da precipitação do submédio em cerca de 50\% de 2012 a 2015 em relação à série de 2007 a 2011.

Em referência à descarga de sedimentos, percebe-se a mudança da variabilidade da condutividade em P1 e P2 (Kruskal-Wallis, P < 0,05), em comparação ao período da Qred (Dunn, $\mathrm{P}<0,05)$. Enquanto que, a condutividade de P3 não sofreu alteração em relação à época da Qred. Semelhante padrão foi descrito por Doretto et al. (2019), no término da operação de descarga de fundo de reservatório em um corpo hídrico. É óbvio que, para a massa líquida dos ecossistemas aquáticos a jusante, houve a transferência dos íons adsorvidos nos sedimentos da descarga do reservatório, com consequente aumento da condutividade (Frémion et al., 2016).

\section{Transparência}

Na redução de vazão-Qred, a mediana da transparência de P1 teve um acréscimo de 1,1m, ou seja, os níveis aumentaram devido à diminuição de entrada de sedimentos através do escoamento superficial na região semiárida da bacia hidrográfica (Medeiros et al., 2016; Mosley et al., 2012). Já as medianas de P2 e P3 reduziram (Figura 6c), segundo Martins et al. (2019), a contínua redução de vazão do rio São Francisco também conduziu à concentração de sedimentos no principal canal do reservatório de Sobradinho, à montante de Xingó, acarretando a desconexão com as regiões próximas à barragem. Essa falta de ligação impediu a renovação das águas na parte ocidental, afetando as condições estéticas e o acesso à água potável.

A recepção da carga de sólidos levou à abrupta mudança da variação da transparência em P1 (Kruskal-Wallis, $\mathrm{P}=0,024$ ), a tal ponto da transparência apresentar heterogeneidade temporal com o período de Qred (Dunn, $\mathrm{P}<0,05$ ), nesse mesmo sentido, na Tabela 5, nota-se o decaimento em termos de mediana em 2,4 m e na Figura $6 \mathrm{c}$ visualiza-se o menor valor extremo $(0,8 \mathrm{~m})$ da história limnológica dessa variável em P1. Nessa mesma Figura, nota-se a degradação da mediana em P2 (Qref-4,5m>Qred3,6m>Rsed 2,6) e P3 (Qref-3,7m>Qred-2,6m>Rsed-1,9m).

Na Rsed, defende-se que, dois eventos alteraram os padrões de transparência das águas do reservatório de Xingó, o primeiro foi à descarga de fundo do reservatório Delmiro Gouveia e o 
segundo efeito foi à proliferação de microalgas. 0 lançamento de cargas de sedimentos tem como consequência, em rios e reservatórios a jusante, concentrações de alta magnitude de sólidos suspensos e lógico, redução da transparência (Baoligao et al., 2016; Chung et al., 2008; Doretto et al., 2019). O segundo evento, florações de algas, acarreta, segundo Braga et al. (2015), a diminuição da transparência.

pH

0 pH de P1 e P2 na vazão-Qred apresentaram semelhante padrão de distribuição ao período da Qref (Figura 6d), enquanto que, o perfil da distribuição do pH em P3 apresentou diferença em relação à Qref (Dunn, $\mathrm{P}<0,05)$, demonstrando uma elevação de 0,8 em sua mediana. 0 acréscimo do pH em P3 pode ter sido motivado por proliferação de microalgas ou pelo aumento da taxa de evaporação (TUNDISI e TUNDISI, 2016).

Após a recepção de sedimentos, o teste de Kruskal-Wallis $(\mathrm{P}<0,05)$ mostrou distribuição heterogênea do pH em P1 e P2 e o teste de Dunn $(\mathrm{P}<0,05)$ identificou que o pH do período da Rsed diferiu do $\mathrm{pH}$ do período da Qref em P1 e P2, bem como, também divergiu do intervalo de tempo da Qred em P1. Na análise da Figura 6d, percebe-se que o pH de P3 na época da Rsed mostrou padrão semelhante à época da Qref. Em P1 e P2, inicialmente, o pH sofreu influências da composição físicoquímica dos sedimentos do fundo da barragem Delmiro Gouveia e subsequentemente da proliferação do fitoplâncton.

\section{Oxigênio dissolvido-OD}

No contexto da redução da vazão, a concentração de OD em P1, P2 e P3 se elevaram (Figura 6e), com o teste de Dunn $(\mathrm{P}<0,05)$ indicando heterogeneidade do OD de P2 e P3 em relação à época da Qref, tal elevação pode ter associação com a proliferação de microalgas na Qred.

Na Rsed, a mediana de P1, P2 e P3 diminuíram em relação a Qred, já em P1 e P2 a descarga de sedimentos seguida da proliferação de algas foram responsáveis pela maior dispersão dos dados, que apresentaram valores extremos superiores e inferiores (Figura 6e). Os outliers superiores coincidiram com o pico da densidade algal (mai/2015), já os outliers inferiores ocorreram em dois momentos distintos, o primeiro foi logo após a ressuspensão dos sedimentos (abr/2015) e o segundo após cerca de três meses da notória proliferação dos fitoplânctons.

Pressupõe-se que inicialmente os níveis de oxigênio dissolvido reduziram para oxidar a matéria orgânica presente na ressuspensão dos sedimentos (Baoligao et al., 2016; Chung et al., 2008; Doretto et al., 2019), as seguintes evidências apoiam essa tese: a concentração da matéria orgânica em 3,70\% nos sólidos transferidos para o reservatório de Xingó (Companhia Hidrelétrica do São Francisco, 2014) e a mudança da DBO em P1, que foi de 1,5 $\pm 0,6 \mathrm{mg} / \mathrm{L}$ na Qred para o valor máximo de 74,6 mg/L em abr/2015. Após esse valor máximo, a DBO retornou a seus padrões normais, no entanto, no fim de mai/2015 a DBO volta a apresentar um valor de 18,6 mg/L e por consequência em P1 percebe-se o déficit até 3,90 mg/L (Figura 6e), provavelmente, a DBO para decompor a massa do excesso de fitoplâncton reduziu a concentração de oxigênio.

\section{Fósforo total}

Houve decaimento da concentração de fósforo total em P1 e P2 na época da Qred (Figura 6f), nesses ambientes lóticos, segundo Mosley et al. (2012), a redução de vazão promove o decréscimo quantitativo de fósforo total, em virtude da diminuição do transporte através do escoamento superficial. Em contraste, em ambiente lêntico, tal como em P3, em consonância com Mosley et al. (2012), a redução de volume justifica o aumento da concentração desse nutriente.

Após a recepção de sedimentos, em P1, a concentração de fósforo total apresentou o maior outlier de sua série histórica (Figura 6f), maior quantidade de valores extremos superiores e maior mediana em comparação ao período de Qred. Semelhante a P1, em P2 a mediana se elevou em relação ao período da Qred, porém, não houve picos tão elevados. Diferente de P1 e P2, em P3, a mediana diminui, em relação à época da Qred, apesar disso, apresentou distribuição similar ao período da Qred.

Segundo as análises sedimentológicas da Companhia Hidrelétrica do São Francisco (2014): no reservatório Delmiro Gouveia, o fósforo total variou de 9.000,0 a 98.400,0 $\mu \mathrm{g} / \mathrm{kg}$, sendo os valores 
mais altos encontrados no seu centro. Tais valores foram superiores aos sedimentos localizados na cabeceira do reservatório de Xingó, que variaram de 16.900,0 a 43.090,0 $\mu \mathrm{g} / \mathrm{kg}$.

A consequência imediata dessa descarga de sedimentos foi à elevação da concentração de fósforo total nas águas da seção anterior do reservatório de Xingó (Instituto Brasileiro do Meio Ambiente e dos Recursos Naturais Renováveis, 2015). Ao longo do tempo, a ressuspensão de compostos de fósforo pode representar a mais importante fonte desse nutriente para a biota aquática, em virtude da facilidade de assimilação de fósforo inorgânico dissolvido ( $\mathrm{PO}_{4}{ }^{3-}$ ) pelo fitoplâncton (Peter et al., 2014).

\section{Estado trófico}

A Tabela 6 apresenta a vazão média mensal e o estado trófico do reservatório de Xingó, nos três pontos, durante os três períodos estudados, vazão de referência (Qref: 2008 a 2010), vazão reduzida (Qred: jun/2013 a jan/2015) e após a recepção de sedimentos (Rsed: fev/2015 a fev/2016).

\section{Na vazão de referência}

Verificou-se que durante o período da vazão de referência o estado trófico do reservatório era predominantemente oligotrófico e mesotrófico, com predomínio do oligotrófico. Somente em P3, localizado num meandro em ambiente lêntico, foi verificado uma ocorrência de estado eutrófico em jun/2010. Em referência a sazonalidade, P1 e P2 foi oligotrófico de setembro a dezembro e mesotrófico de março a junho, a exceção foi à ocorrência, em P2, da mesotrofia em set/2009. P3, geralmente, foi oligotrófico em dezembro e mesotrófico de março a setembro.

Em ambientes lóticos como P1 e P2, a sazonalidade da trofia coincidiu com a sazonalidade da precipitação da bacia de drenagem do reservatório de Xingó, portanto, o período seco de agosto a dezembro abarcou o período de ocorrência da oligotrofia e o período úmido de março a julho englobou o período de mesotrofia. Diferente de P1 e P2, a mesotrofia em P3 aconteceu de março a setembro, o prolongamento da mesotrofia, provavelmente, aconteceu como reposta da baixa renovação das águas de P3. Assim, a frequência de ocorrência diferiu entre os ambientes lóticos (P1 e P2) e lênticos (P3), no entanto, em ambos o estado nutricional sofreu fortes influências do regime de chuvas da bacia de drenagem do reservatório de Xingó.

\section{Após redução de vazão e a recepção de sedimentos}

Após a recepção da carga de sedimentos, observa-se o enriquecimento nutricional das águas de P1, com o aumento considerável da frequência de ocorrência do grau eutrófico, que passou de 21,4\% na Qred para 50\% na Rsed. Já a frequência de eutrofia em P2 passou de 21,4\% na Qred para 30\% na Rsed. Enquanto que, em P3 a frequência da eutrofia foi 64,3\% na Qred e 66,8\% na Rsed, praticamente, permanecendo constante.

\section{Fitoplânctons}

Na Vazão de referência, as espécies de fitoplâncton mais abundantes foram Sphaerocystis schroeteri, Aulacoseira ambígua, Aulacoseira granulata, Cylindrospermopsis raciborskii e Fragilaria crotonensis, com predominância desta última. A F. crotonensis é uma espécie do gênero de diatomáceas comum em águas doces e salgadas, bem como é típica de ambientes temperado e mesotrófico. Mas vale salientar a presença da $C$. raciborskii, que foi a segunda espécie mais abundante e segundo Tucci \& Sant'Anna (2003), essas cianobactérias (Ordem Nostocales) formam florações com alto potencial tóxico e são cada vez mais frequentes em reservatórios brasileiros, em virtude da sua alta competitividade em ambientes tropicais eutrofizados. A Tabela 7 apresenta a trofia e abundância do fitoplâncton em P1 e P2 na vazão de referência.

Após a descarga de sedimentos, verificou-se o predomínio do estado eutrófico em P1 e P3 e mesotrófico em P2. Com relação aos fitoplânctons verificou-se a presença da F. crotonensis somente na primeira quinzena de abril, mesmo assim em pouca abundância, além disso, percebe-se o surgimento da $C$. furcoides, que não havia sido observada na Qref, e o estabelecimento da cianobactéria $C$. raciborskii, sendo a presença destas duas espécies as mais frequentes no lago. A Tabela 8 apresenta a trofia e abundância do fitoplâncton em P1 e P2 após a recepção de sedimentos. 
Tabela 6 - Análise da trofia nos períodos estudados.

\begin{tabular}{|c|c|c|c|c|}
\hline \multicolumn{5}{|c|}{ Vazão de referência } \\
\hline Mês/Ano & $\mathrm{m}^{3} / \mathrm{s}$ & P 1 & P 2 & P 3 \\
\hline Dez/2007 & 2.057 & Oligo & Oligo & Oligo \\
\hline Mar/2008 & 1.078 & Oligo & Oligo & Oligo \\
\hline Jun/2008 & 1.3965 & Meso & Meso & Meso \\
\hline Set/2008 & 1.921 & Oligo & Oligo & Meso \\
\hline Dez/2008 & 1.805 & Oligo & Oligo & Oligo \\
\hline Mar/2009 & 1.796 & Meso & Meso & Meso \\
\hline Jun/2009 & 2.024 & Meso & Meso & Meso \\
\hline Set/2009 & 1.930 & Oligo & Meso & Meso \\
\hline Dez/2009 & 2.169 & Oligo & Oligo & Oligo \\
\hline Mar/2010 & 1.881 & Meso & Oligo & Meso \\
\hline Jun/2010 & 1.427 & Meso & Meso & Eu \\
\hline Set/2010 & 1.726 & Oligo & Oligo & Meso \\
\hline \multicolumn{5}{|c|}{ Vazão reduzida } \\
\hline Mês/Ano & $\mathrm{m}^{3} / \mathrm{s}$ & P 1 & P 2 & P 3 \\
\hline Jun/2013 & 1.130 & Oligo & Oligo & $\mathrm{Eu}$ \\
\hline Jul/2013 & 1.357 & Oligo & Meso & $\mathrm{Eu}$ \\
\hline Ago/2013 & 1.225 & Meso & Meso & $\mathrm{Eu}$ \\
\hline Set/2013 & 1.291 & Meso & Meso & $\mathrm{Eu}$ \\
\hline Out/2013 & $1.32,8$ & Meso & Meso & $\mathrm{Eu}$ \\
\hline Nov/2013 & 1.210 & Oligo & Meso & Oligo \\
\hline Dez/2013 & 1.086 & Meso & Meso & Oligo \\
\hline Jan/2014 & 1.134 & $\mathrm{Eu}$ & $\mathrm{Eu}$ & $\mathrm{Eu}$ \\
\hline $\mathrm{Abr} / 2014$ & 1.102 & Ultraoligo & Ultraoligo & Ultraoligo \\
\hline Set/2014 & 1.067 & Oligo & Oligo & $\mathrm{Eu}$ \\
\hline Out/2014 & 1.107 & $\mathrm{Eu}$ & $\mathrm{Eu}$ & $\mathrm{Eu}$ \\
\hline Nov/2014 & 1.079 & Meso & Oligo & Oligo \\
\hline Dez/2014 & 1.076 & Ultraoligo & Oligo & Oligo \\
\hline Jan/2015 & 1.065 & $\mathrm{Eu}$ & $\mathrm{Eu}$ & $\mathrm{Eu}$ \\
\hline \multicolumn{5}{|c|}{ Recepção de sedimentos } \\
\hline Mês/Ano & $\mathrm{m}^{3} / \mathrm{s}$ & P 1 & P 2 & P 3 \\
\hline Fev/2015 & 1.057 & Oligo & $\mathrm{Eu}$ & $\mathrm{Eu}$ \\
\hline Mar/2015 & 1.067 & Oligo & Meso & Oligo \\
\hline Abr/2015 & 1.003 & $\mathrm{Eu}$ & Meso & $\mathrm{Eu}$ \\
\hline Mai/2015 & 1.077 & $\mathrm{Eu}$ & Meso & \\
\hline Jun/2015 & 862 & $\mathrm{Eu}$ & Meso & $\mathrm{Eu}$ \\
\hline Jul/2015 & 858 & Meso & Meso & Meso \\
\hline Ago/2015 & 860,0 & Meso & Meso & $\mathrm{Eu}$ \\
\hline Set/2015 & 858,0 & $\mathrm{Eu}$ & $\mathrm{Eu}$ & $\mathrm{Eu}$ \\
\hline Jan/2016 & 900,5 & $\mathrm{Eu}$ & Meso & Oligo \\
\hline Fev/2016 & 795,0 & Oligo & $\mathrm{Eu}$ & $\mathrm{Eu}$ \\
\hline
\end{tabular}


Tabela 7 - Abundância do fitoplâncton do reservatório de Xingó na vazão de referência (2007/2010).

\begin{tabular}{c|c|c}
\hline Período & Trofia & Espécies mais abundantes \\
\hline Dez/2007 & Oligo & Q. chodatii, S. schroeteri e F. crotonensis \\
\hline Mar/2008 & Oligo & $\begin{array}{c}\text { C. vulgaris, S. schroeteri, Aulacoseira sp., F. crotonensis } \text { e } \text {. } \\
\text { longiseta }\end{array}$ \\
\hline Jun/2008 & Meso & A. ambigua, A. granulata e F. crotonensis \\
\hline Set/2008 & Oligo-Meso & R. mediterranea e C. raciborskii \\
\hline Dez/2008 & Oligo & F. crotonensis \\
\hline Mar/2009 & Meso & P. gardhii e A. granulata \\
\hline Jun/2009 & Meso & A. ambigua e A. granulata \\
\hline Set/2009 & Oligo-Meso & Anabaena sp., Aphanizomenon sp., C.raciborskii, F. crotonensis, \\
Jun/2010 & Meso-Eu & C. raciborskii \\
\hline Set/2010 & Oligo-Meso & C. raciborskii \\
\hline Dez/2010 & & F. crotonensis \\
\hline
\end{tabular}

Tabela 8 - Abundância do fitoplâncton de P1 e P2 após a recepção de sedimentos (abr/2015 a fev/2016).

\begin{tabular}{|c|c|c|c|c|}
\hline \multicolumn{5}{|c|}{ Ponto 1} \\
\hline Período & Trofia & Espécies & Categoria & Cél/mL \\
\hline \multirow{3}{*}{16 a 23 abr/2015 } & \multirow{3}{*}{$\mathrm{Eu}$} & F. crotonensis & Pouco abundante & \multirow{3}{*}{13.754} \\
\hline & & C. furcoides & Dominante & \\
\hline & & C. raciborskii & Rara & \\
\hline \multirow{3}{*}{24 a 30 abr/2015 } & \multirow{3}{*}{ Meso } & A. granulata & Pouco abundante & \multirow{3}{*}{5.141} \\
\hline & & C. furcoides & Abundante & \\
\hline & & C. raciborskii & Pouco abundante & \\
\hline \multirow{3}{*}{$06 / 05 / 2015$} & \multirow{3}{*}{ Meso } & A. granulata & Rara & \multirow{3}{*}{8.745} \\
\hline & & C. furcoides & Rara & \\
\hline & & C. raciborskii & Dominante & \\
\hline \multirow{2}{*}{$14 / 05 / 2015$} & \multirow{2}{*}{$\mathrm{Eu}$} & C. furcoides & Abundante & \multirow{2}{*}{58.655} \\
\hline & & C. raciborskii & Pouco abundante & \\
\hline \multirow{2}{*}{15 a 31 mai/2015 } & \multirow{2}{*}{$\mathrm{Eu}$} & C. furcoides & Rara & \multirow{2}{*}{319.99} \\
\hline & & C. raciborskii & Abundante & \\
\hline \multirow{2}{*}{$16 / 06 / 2015$} & \multirow{2}{*}{ Meso } & C. furcoides & Pouco abundante & \multirow{2}{*}{77.735} \\
\hline & & C. raciborskii & Abundante & \\
\hline $19 / 01 / 2016$ & $\mathrm{Eu}$ & C. raciborskii & Dominante & 52.64 \\
\hline \multirow{2}{*}{19 a $27 \mathrm{fev} / 2016$} & \multirow{2}{*}{ Oligo } & Geitlerinema sp. & Dominante & \multirow{2}{*}{46.702} \\
\hline & & C. raciborskii & Pouco abundante & \\
\hline \multicolumn{5}{|c|}{ Ponto 2} \\
\hline Período & Trofia & Espécies & Categoria & Cél/mL \\
\hline \multirow{3}{*}{16 a 23 abr/2015 } & \multirow{3}{*}{ Meso } & F. crotonensis & Pouco abundante & \multirow{3}{*}{4.377} \\
\hline & & C. furcoides & Abundante & \\
\hline & & C. raciborskii & Rara & \\
\hline \multirow{2}{*}{24 a 30 abr/2015 } & Meso & C. furcoides & Pouco abundante & 17287 \\
\hline & Meso & C. raciborskii & Abundante & 17.287 \\
\hline $06 / 05 / 2015$ & Meso & C. furcoides & Rara & 44267 \\
\hline $06 / 05 / 2015$ & Meso & C. raciborskii & Dominante & 442.67 \\
\hline $14 / 05 / 2015$ & Meso & C. furcoides & Pouco abundante & 16454 \\
\hline $14 / 05 / 2015$ & Meso & C. raciborskii & Dominante & 16.454 \\
\hline 15 a $31 \mathrm{mai} / 2015$ & Meso & C. furcoides & Pouco abundante & 9.549 \\
\hline 15 d 31 mal $\angle 015$ & Meso & C. raciborskii & Dominante & 9.549 \\
\hline $16 / 06 / 2015$ & Meso & C. furcoides & Rara & 1.124 \\
\hline $10 / 00 / 2013$ & Meso & C. raciborskii & Dominante & 1.124 \\
\hline $19 / 01 / 2016$ & Meso & C. raciborskii & Dominante & 70.547 \\
\hline & & C. raciborskii & Pouco abundante & \\
\hline 19 a $27 \mathrm{fev} / 2016$ & $\mathrm{Eu}$ & Geitlerinema sp. & Dominante & 175.108 \\
\hline & & Oscillatoria sp. & Pouco abundante & \\
\hline
\end{tabular}


C. furcoides foram detectados nos reservatórios de Xingó e Delmiro Gouveia em 2013 (Instituto Brasileiro do Meio Ambiente e dos Recursos Naturais Renováveis, 2015), similarmente aos eventos que antecederam o primeiro registro de floração de C. furcoides em Xingó, Crossetti et al. (2019) também constataram um período de seca extrema seguida de perturbações nos sedimentos, como consequência os cistos migraram dos sedimentos para a superfície das águas, encontrando condições para seu desenvolvimento (Cavalcante et al., 2016; Matsumura-Tundisi et al., 2010). Tal floração de Ceratium atingiu uma extensão visível de $28 \mathrm{~km}$ da cabeceira até a seção intermediária do reservatório de Xingó.

\section{Correlação das variáveis limnológicas com Cylindropermopsis raciborskii e Ceratium furcoides.}

A Tabela 9 apresenta o estudo estatístico de correlação entre a densidade das espécies Cylindropermopsis raciborskii e Ceratium furcoides com as variáveis limnológicas.

Tabela 9 - Coeficiente de Pearson $(\alpha=0,05)$ e valor P do teste de correlação entre as variáveis físicas e químicas e o fitoplâncton de P1 e P2 após a recepção da descarga de fundo (abril/2015 a fevereiro/2016).

\begin{tabular}{|c|c|c|c|c|}
\hline \multicolumn{5}{|c|}{ Ponto 1} \\
\hline Variável & n & C. furcoides & C. raciborskii & Total (Cél/mL) \\
\hline \multirow{2}{*}{ Temperatura $\left({ }^{\circ} \mathrm{C}\right)$} & \multirow{2}{*}{44} & $r=-0,292$ & $r=0,218$ & $r=0,195$ \\
\hline & & $P=0,0547$ & $P=0,155$ & $P=0,206$ \\
\hline \multirow{2}{*}{ Condutividade $(\mu \mathrm{S} / \mathrm{cm})$} & \multirow{2}{*}{42} & $r=-0,339$ & $r=-0,108$ & $r=-0,0693$ \\
\hline & & $P=0,0279$ & $P=0,495$ & $P=0,663$ \\
\hline \multirow{2}{*}{ Transparência (m) } & \multirow{2}{*}{12} & $r=-0,400$ & $r=0,340$ & $r=0,809$ \\
\hline & & $P=0,198$ & $P=0,280$ & $P=0,00143$ \\
\hline \multirow{2}{*}{ Turbidez (UNT) } & \multirow{2}{*}{11} & $r=-0,194$ & $r=0,934$ & $r=0,633$ \\
\hline & & $P=0,568$ & $P=0,0000261$ & $P=0,0367$ \\
\hline \multirow{2}{*}{$\mathrm{pH}$} & \multirow{2}{*}{44} & $r=0,360$ & $r=-0,224$ & $r=-0,218$ \\
\hline & & $P=0,0164$ & $P=0,144$ & $P=0,155$ \\
\hline \multirow{2}{*}{ Oxigênio dissolvido (mg/L) } & \multirow{2}{*}{44} & $r=0,332$ & $r=-0,203$ & $r=-0,207$ \\
\hline & & $P=0,0276$ & $P=0,187$ & $P=0,177$ \\
\hline \multirow{2}{*}{ Fósforo total $(\mu \mathrm{g} / \mathrm{L})$} & \multirow{2}{*}{42} & $r=0,565$ & $r=-0,129$ & $r=-0,113$ \\
\hline & & $P=0,0000964$ & $P=0,416$ & $P=0,478$ \\
\hline \multicolumn{5}{|c|}{ Ponto 2} \\
\hline Variável & $\mathbf{n}$ & C. furcoides & C. raciborskii & Total (Cél/mL) \\
\hline \multirow{2}{*}{ Temperatura $\left({ }^{\circ} \mathrm{C}\right)$} & \multirow{2}{*}{39} & $r=-0,101$ & $r=0,630$ & $r=0,622$ \\
\hline & & $P=0,543$ & $P=0,0000175$ & $P=0,0000239$ \\
\hline \multirow{2}{*}{ Condutividade $(\mu \mathrm{S} / \mathrm{cm})$} & \multirow{2}{*}{39} & $r=0,0406$ & $r=-0,856$ & $r=-0,240$ \\
\hline & & $P=0,806$ & $P=3,604 E-12$ & $P=0,142$ \\
\hline \multirow{2}{*}{ Transparência (m) } & \multirow{2}{*}{10} & $r=-0,0720$ & $r=-0,201$ & $r=-0,372$ \\
\hline & & $P=0,843$ & $P=0,578$ & $P=0,290$ \\
\hline \multirow{2}{*}{ Turbidez (UNT) } & \multirow{2}{*}{11} & $r=-0,183$ & $r=0,504$ & $r=0,0905$ \\
\hline & & $P=0,590$ & $P=0,114$ & $P=0,791$ \\
\hline \multirow{2}{*}{$\mathrm{pH}$} & \multirow{2}{*}{39} & $r=0,389$ & $r=-0,115$ & $r=-0,279$ \\
\hline & & $P=0,0145$ & $P=0,486$ & $P=0,0860$ \\
\hline \multirow{2}{*}{ Oxigênio dissolvido (mg/L) } & \multirow{2}{*}{39} & $r=0,00939$ & $r=-0,311$ & $r=0,392$ \\
\hline & & $P=0,955$ & $P=0,0539$ & $P=0,0136$ \\
\hline \multirow{2}{*}{ Fósforo total ( $\mu \mathrm{g} / \mathrm{L})$} & \multirow{2}{*}{39} & $r=0,0697$ & $r=0,0656$ & $r=0,381$ \\
\hline & & $P=0,678$ & $P=0,696$ & $P=0,0182$ \\
\hline
\end{tabular}

Em P1 e P2, C. raciborskii foram correlacionadas positivamente com a temperatura e turbidez, ao passo que foi relacionada negativamente com pH e OD, C. raciborskii foi independente da concentração 
de fósforo total. Em P1 e P2, C. furcoides foram correlacionadas positivamente com pH e OD, enquanto C. furcoides foram associados negativamente com a temperatura e turbidez. Em P1, C. furcoides foi associado com relevância com a concentração de fósforo total, mas não mostrou clara relação em P2.

Após a recepção de sedimentos, a temperatura das águas do reservatório de Xingó foi superior a $25^{\circ} \mathrm{C}$ (Figura 6a). A população de C. raciborskii cresce e aumenta em temperaturas acima de $25,0^{\circ} \mathrm{C}$ (Padisak, 1997), segundo estes autores (Cavalcante et al., 2016, Tucci \& Sant'Anna, 2003) a proliferação dessa cianobactéria também coincidiu com períodos de temperaturas elevadas. Silva et al. (2018) citam que Ceratium também se desenvolve em temperaturas acima de $25^{\circ} \mathrm{C}$, porém, na competição entre essas duas espécies, o teste de correlação mostrou que valores mais altos de temperatura conferem vantagens a Cylindropermopsis.

No período de maio a jun/2015, a turbidez em P1 $(7,93 \pm 6,09$ UNT) foi maior que em P2 (2,87 \pm 0,96 UNT). Após chuvas de $197 \mathrm{~mm}$ em jan/2016 (média de $39 \mathrm{~mm}$ em jan, Figura 3), houve picos de turbidez em P1 (58,1 UNT), P2 (107,3 UNT) e P3 (92,8 UNT), porém, a turbidez na estação Delmiro Gouveia foi 1,27 UNT.

Nesses dois períodos, em P1, P2 e P3, a proliferação de Cylindropermopsis reafirma que essa cianobactéria tolera uma ampla faixa de luminosidade (Burford, et al, 2016; Tucci \& Sant'Anna, 2003). Isso é em virtude de um mecanismo cromático adaptativo, que lhe confere habilidade de persistir em florações muito densas (Padisak, 1997), tais como as florações de $C$. furcoides. Bem como, capacita Cylindropermopsis a se desenvolver em picos de turbidez ocasionados após chuvas de alta magnitude.

Em relação a associação de Ceratium com a turbidez, a correlação negativa em P1 e P2 (Tabela 9) e a ocorrência do dinoflagelado na estação Delmiro Gouveia (Tabela 10) indicam que Ceratium depende da disponibilidade de luz para aumentar a sua densidade (Crossetti et al., 2019).

A correlação positiva de $C$. raciborskii e negativa de $C$. furcoides com a turbidez (Tabela 9), assim como, os dados destacados na Tabela 10 mostram, claramente, que a turbidez é um fator preponderante na disputa ecológica entre essas duas espécies. Além disso, destaca-se que valores de turbidez a partir de 58,1 UNT (Tabela 10) foram limitantes para a ocorrência de Ceratium, ao contrário disso, tais picos de turbidez foram decisivos para a supremacia de Cylindropermopsis.

Tabela 10 - Interferência da turbidez na associação ecológica de $C$. furcoides e C. raciborskii, após pluviosidade de alta magnitude na bacia do reservatório de Xingó, jan/2016.

\begin{tabular}{|c|c|c|c|c|c|c|c|}
\hline Estação & Ambiente & UNT & Trofia & Espécie & Categoria & (\%) & Cél / mL \\
\hline $\mathrm{P} 1$ & Lótico & 58,1 & $\mathrm{Eu}$ & C. raciborskii & Dominante & 95,7 & 52.640 \\
\hline $\mathrm{P} 2$ & Lótico & 107,3 & Meso & C. raciborskii & Dominante & 93,4 & 70.547 \\
\hline \multirow{2}{*}{$\begin{array}{l}\text { Delmiro } \\
\text { Gouveia }\end{array}$} & \multirow[b]{2}{*}{ Lêntico } & \multirow[b]{2}{*}{1,27} & \multirow[b]{2}{*}{$\mathrm{Eu}$} & C. furcoides & Dominante & 77,0 & \multirow[b]{2}{*}{178.235} \\
\hline & & & & C. raciborskii & $\begin{array}{c}\text { Pouco } \\
\text { abundante }\end{array}$ & 22,0 & \\
\hline P3 & Lêntico & 92,8 & Oligo & C. raciborskii & Dominante & 98,9 & 106.585 \\
\hline
\end{tabular}

O pH em P1 foi de 7,1-10,0 e em P2 de 7,1-9,5. Segundo Padisak (1997), C. raciborskii geralmente ocorre em pH de 8,0 -8,7. Segundo Cavalcante et al. (2016), picos de Ceratium foram registrados em condições alcalinas com pH de 8,0 a 10,0. A faixa semelhante de pH para a proliferação do dinoflagelado e a cianobactéria conduz a conclusão de que o pH é um fator secundário nessa disputa ecológica. Contudo, a correlação positiva com Ceratium e negativa com Cylindropermopsis pode evidenciar que o dinoflagelado se prolifera em condições mais alcalinas, enquanto condições neutras ou levemente alcalinas tendem a favorecer Cylindropermopsis.

Após a recepção de sedimentos, o OD em P1 foi de 3,9-13,0 mg/L e em P2 foi de 5,9-9,8 mg/L. E pela análise da Figura 6e, nota-se que as águas de P1 foram mais oxigenadas que as águas de P2. Em $P 1$, o teste de Pearson $(n=44, r=0,332$ e $P=0,0276)$ confirma a tendência de beneficiamento de Ceratium em águas com elevadas concentrações de oxigênio dissolvido, porém essa mesma relação foi desprezível em P2. Segundo Cavalcante et al. (2016), águas com OD>5,0 mg/L também são um fator importante para o desenvolvimento de Ceratium. Em relação à Cylindrospemopsis, a correlação negativa mostra que os menores valores de OD em P1 e P2 tendem a favorecer a cianobactéria.

Após a recepção de sedimentos, fósforo total em P1 foi de 0,0-250,0 $\mu \mathrm{g} / \mathrm{L}$ e em P2 foi de 23,0200,9 $\mu \mathrm{g} / \mathrm{L}$, com vários picos (acima de $100 \mu \mathrm{g} / \mathrm{L}$ ) de fósforo total em P1 (Figura 6f). Estes autores 
(Cavalcante et al., 2016; Crossetti et al., 2019; Matsumura-Tundisi et al., 2010) defendem que valores extremos de fósforo total favorecem a proliferação de Ceratium. Em P1, o teste de Pearson ( $n=42, r=$ 0,565 e $\mathrm{P}=0,0000964$ ) também confirmou essa tese.

Em referência à Cylindrospemopsis, a associação desprezível em P1 e P2 (Tabela 9) mostram que essa espécie tem a capacidade de absorver rapidamente o fosfato mesmo em baixas concentrações, possui a habilidade de migrar para águas profundas ricas em nutrientes e também detém o mecanismo de estocar compostos de fósforos (Burford et al., 2016; Padisak, 1997).

$\mathrm{Na}$ ecologia dessas microalgas, conclui-se que baixas concentrações de fósforo favoreceram a dominância de Cylindrospemopsis (Tucci \& Sant'Anna, 2003), ao passo que picos de fósforo total favorecem a proliferação de Ceratium.

Na qualidade da água de Xingó, a associação ecológica dessas duas espécies, também, chama a atenção para o grau de perigo para o sistema de abastecimento público, já que, a proliferação de microalgas interrompeu o fornecimento de água potável a cerca de 184.000 habitantes, no Alto Sertão de Alagoas, por um período, aproximadamente, de 15 dias. Em decorrência dos sabores/odores fétidos de substâncias presentes em C. furcoides (Silva et al., 2018), obstrução e sobrecarga dos filtros da ETA, e, sobretudo, ao potencial tóxico da floração, tendo em vista que, algumas cepas de $C$. raciborskii produzem hepatoxinas (Padisak, 1997).

\section{CONCLUSÕES}

Há indicações de que a extrema redução de vazão média do rio São Francisco influenciou a diminuição da condutividade, o aumento dos níveis de oxigênio dissolvido, o acréscimo da transparência em P1, a diminuição da transparência em P2 e P3, a elevação do pH em P3, o decaimento de fósforo total em P1 e P2 e o aumento de fósforo total em P3.

As análises estatísticas e dos perfis das variáveis físicas e químicas indicam que a descarga total dos sedimentos do reservatório de montante Delmiro Gouveia resultaram no desequilíbrio térmico, aumento da condutividade e elevação de fósforo total nas seções anterior e intermediária do reservatório de Xingó.

O deplecionamento total do reservatório Delmiro Gouveia seguida da proliferação de algas alteraram os padrões de transparência, $\mathrm{pH}$ e oxigênio dissolvido nas seções anterior e intermediária do reservatório de Xingó.

Diferente das águas da cabeceira e meio do reservatório de Xingó, os resultados mostram que as águas da seção posterior não foram impactadas diretamente pela descarga de sedimentos.

A descarga total dos sedimentos do reservatório de montante Delmiro Gouveia foi o principal fator ambiental para o registro da primeira floração e estabelecimento de Ceratium furcoideis no reservatório de Xingó, o deplecionamento total foi responsável por transferir sedimentos ricos em nutrientes e cistos de Ceratium furcoideis.

Conclui-se que os cistos de Ceratium furcoideis encontraram na superfície das águas do reservatório de Xingó alta concentração de compostos fosfatados, águas bem oxigenadas e disponibilidade de luz para se proliferarem e dominarem o ecossistema aquático.

Portanto, a extrema redução da vazão seguida da recepção da carga de sedimentos diminuiu a riqueza do fitoplâncton, estabelecendo invasão de Ceratium furcoides. Nas florações, Ceratium furcoides competiu diretamente com a cianobactéria potencialmente tóxica Cylindrospemopsis raciborskii. Defende-se que, o autossombreamento da longa e densa proliferação de Ceratium furcoides foi o principal motivo para a sua sucessão ecológica por Cylindrospemopsis raciborskii.

Florações de Ceratium furcoides e Cylindrospemopsis raciborskii requerem a combinação de sistemas eficientes com tecnologias avançadas para o tratamento da água, já que exigem a remoção de compostos orgânicos fétidos e da densa massa de Ceratium furcoides. A ETA, sobretudo, deve remover potenciais toxinas produzidas por algumas cepas de Cylindrospemopsis raciborskii.

\section{REFERÊNCIAS}

Agência Nacional de Águas - ANA. (2018). Hidroweb v 2.0.0.1. Recuperado em 27 de dezembro de 2018, de http://www.snirh.gov.br/ hidroweb/publico/apresentacao.jsf

Agência Nacional de Águas - ANA. (2019). Sala de situação. Recuperado em 20 de abril de 2019, de http://www3.ana.gov.br/ portal/ANA/sala-de-situacao/sao-francisco/sao-francisco-saiba-mais

American Public Health Association - APHA. (2012). Standard methods for the examination of water and wastewater (22nd ed.). Washington: APHA. 
Baoligao, B., Xu, F., Chen, X., Wang, X., \& Chen, W. (2016). Acute impacts of reservoir sediment flushing on fishes in the Yellow River. Journal of Hydro-environment Research, 13, 26-35.

Braga, G. G., Becker, V., Oliveira, J. N. P. D., Mendonça Junior, J. R. D., Bezerra, A. F. D. M., Torres, L. M., Galvão, Â. M. F., \& Mattos, A. (2015). Influence of extended drought on water quality in tropical reservoirs in a semiarid region. Acta Limnologica Brasiliensia, 27(1), 15-23.

Burford, M. A., Beardall, J., Willis, A., Orr, P. T., Magalhaes, V. F., Rangel, L. M., Azevedo, S. M. F. O. E., \& Neilan, B. A. (2016). Understanding the winning strategies used by the bloom-forming cyanobacterium Cylindrospermopsis raciborskii. Harmful Algae, 54, 44-53.

Carlson, R. E. (1977). A trophic state index for lakes. Limnology and Oceanography, 22(2), 361-369.

Cavalcante, K. P., Cardoso, L. S., Sussella, R., \& Becker, V. (2016). Towards a comprehension of Ceratium (Dinophyceae) invasion in Brazilian freshwaters: autecology of $C$. furcoides in subtropical reservoirs. Hydrobiologia, 771(1), 265-280.

Chiogna, G., Skrobanek, P., Narany, T. S., Ludwig, R., \& Stumpp, C. (2018). Effects of the 2017 drought on isotopic and geochemical gradients in the Adige catchment, Italy. The Science of the Total Environment, 645(9), 2436.

Chung, S. W., Ko, I. H., \& Kim, Y. K. (2008). Effect of reservoir flushing on downstream river water quality. Journal of Environmental Management, 86(1), 139-147.

Comitê da Bacia Hidrográfica do Rio São Francisco - CBHSF. (2016). Plano de recursos hídricos da bacia hidrográfica do rio São Francisco 2016-2025. Ago.

Comitê da Bacia Hidrográfica do Rio São Francisco - CBHSF. (2020). Recuperado em 27 de junho de 2020, de https://cbhsaofrancisco.org.br/noticias/cultura_blog/a-usina-hidreletrica-de-xingo/

Companhia Hidrelétrica do São Francisco - CHESF. (2013). 1o relatório mensal: programa de monitoramento do Rio São Francisco durante o período de vazão reduzida. Jun.

Companhia Hidrelétrica do São Francisco - CHESF. (2014). $9^{\circ}$ relatório mensal: programa de monitoramento do Rio São Francisco durante o período de vazão reduzida. Jan.

Companhia Hidrelétrica do São Francisco - CHESF. (2015). $5^{\circ}$ relatório mensal da continuação dos serviços do programa de monitoramento do Rio São Francisco durante o período de vazão reduzida. Jan.

Companhia Hidrelétrica do São Francisco - CHESF. (2016). Recuperado em 1 de fevereiro de 2019, de https://www.chesf.gov.br/SistemaChesf/Pages/SistemaGeracao/Xingo.aspx

Crossetti, L. O., Bicudo, D. C., Bini, L. M., Dala-Corte, R. B., Ferragut, C., \& de Mattos Bicudo, C. E. (2019). Phytoplankton species interactions and invasion by Ceratium furcoides are influenced by extreme drought and water-hyacinth removal in a shallow tropical reservoir. Hydrobiologia, 831(1), 71-85.

Doretto, A., Bo, T., Bona, F., Apostolo, M., Bonetto, D., \& Fenoglio, S. (2019). Effectiveness of artificial floods for benthic community recovery after sediment flushing from a dam. Environmental Monitoring and Assessment, 191(2), 88.

East, A. E., Pess, G. R., Bountry, J. A., Magirl, C. S., Ritchie, A. C., Logan, J. B., Randle, T. J., Mastin, M. C., Minear, J. T., Duda, J. J., Liermann, M. C., McHenry, M. L., Beechie, T. J., \& Shafroth, P. B. (2015). Large-scale dam removal on the Elwha River, Washington, USA: river channel and floodplain geomorphic change. Geomorphology, $228,765-786$.

Frémion, F., Courtin-Nomade, A., Bordas, F., Lenain, J.-F., Jugé, P., Kestens, T., \& Mourier, B. (2016). Impact of sediments resuspension on metal solubilization and water quality during recurrent reservoir sluicing management. The Science of the Total Environment, 562, 201-215.

Fundação Apolônio Salles de Desenvolvimento Educacional - FADURPE. (2009). Inventário dos Ecossistemas Aquáticos do Baixo São Francisco. Reservatório de Xingó e Baixo São Francisco. 1ํo Relatório anual. Recife, PE.

Fundação Apolônio Salles de Desenvolvimento Educacional - FADURPE. (2010). Inventário dos Ecossistemas Aquáticos do Baixo São Francisco. Reservatório de Xingó e Baixo São Francisco. $2^{\circ}$ Relatório anual. Recife, PE.

Fundação Apolônio Salles de Desenvolvimento Educacional - FADURPE. (2011a). Inventário dos Ecossistemas Aquáticos do Baixo São Francisco. Reservatório de Xingó e Baixo São Francisco. 3o Relatório anual. Recife, PE.

Fundação Apolônio Salles de Desenvolvimento Educacional - FADURPE. (2011b). Inventário dos Ecossistemas Aquáticos do Baixo São Francisco. Reservatório de Xingó e Baixo São Francisco. Relatório trianual: Dezembro de 2007 a Novembro de 2010. Recife, PE. 
Hasle, R. G. (1978). The inverted microscope method. In A. Sournia (Org.), Phytoplankton manual. Paris: United Nations Educational, Scientific, and Cultural Organization.

Instituto Brasileiro de Geografia e Estatística - IBGE. (2018). Recuperado em 25 de novembro de 2018, de https://cidades.ibge.gov.br/brasil/al

Instituto Brasileiro do Meio Ambiente e dos Recursos Naturais Renováveis - IBAMA. (2015). Núcleo de licenciamento ambiental - PE. PAR. 02019.000015/2015-99 NLA/PE/IBAMA, assunto: acompanhamento das atividades de deplecionamento e reenchimento do reservatório Delmiro Gouveia. Brasília.

Jones, E., \& Van Vliet, M. T. H. (2018). Drought impacts on river salinity in the southern US: implications for water scarcity. The Science of the Total Environment, 644, 844-853.

Jong, P., Tanajura, C. A. S., Sánchez, A. S., Dargaville, R., Kiperstok, A., \& Torres, E. A. (2018). Hydroelectric production from Brazil's São Francisco River could cease due to climate change and inter-annual variability. The Science of the Total Environment, 634(9)

Lehman, P. W., Kurobe, T., Lesmeister, S., Baxa, D., Tung, A., \& Teh, S. J. (2017). Impacts of the 2014 severe drought on the Microcystis bloom in San Francisco Estuary. Harmful Algae, 63, 94-108.

Li, T., Li, S., Liang, C., Bush, R. T., Xiong, L., \& Jiang, Y. (2018). A comparative assessment of Australia's Lower Lakes water quality under extreme drought and post-drought conditions using multivariate statistical techniques. Journal of Cleaner Production, 190, 1-11.

Martins, V. S., Kaleita, A., Barbosa, C. C. F., Fassoni-Andrade, A. C., Lobo, F. L., \& Novo, E. M. L. M. (2019). Remote sensing of large reservoir in the drought years: implications on surface water change and turbidity variability of Sobradinho reservoir (Northeast Brazil). Remote Sensing Applications: Society and Environment, 13, 275-288.

Matsumura-Tundisi, T., Tundisi, J. G., Luzia, A. P., \& Degani, R. M. (2010). Occurrence of Ceratium furcoides (Levander) Langhans 1925 bloom at the Billings Reservoir, São Paulo State, Brazil. Brazilian Journal of Biology = Revista Brasileira de Biologia, 70(3), 825-829.

Medeiros, P. R. P., Cavalcante, G. H., Brandini, N., \& Knoppers, B. A. (2016). Inter-annual variability on the water quality in the Lower São Francisco River (NE-Brazil). Acta Limnologica Brasiliensia, 28, e5.

Mosley, L. M. (2015). Drought impacts on the water quality of freshwater systems, review and integration. Earth-Science Reviews, 140, 203-214.

Mosley, L. M., Zammit, B., Leyden, E., Heneker, T. M., Hipsey, M. R., Skinner, D., \& Aldridge, K. T. (2012). The impact of extreme low flows on the water quality of the Lower Murray River and Lakes (South Australia). Water Resources Management, 26(13), 3923-3946.

Padisak, J. (1997). Cylindrospermopsis raciborskii (Woloszynska) Seenayya et Subba Raju, an expanding, highly adaptive cyanobacterium: worldwide distribution and review of its ecology. Archiv Für Hydrobiologie Supplementband Monographische Beitrage, 107(4), 563-593.

Peter, D. H., Castella, E., \& Slaveykova, V. I. (2014). Effects of a reservoir flushing on trace metal partitioning, speciation and benthic invertebrates in the floodplain. Environmental Science. Processes \& Impacts, 16(12), 2692-2702.

Santos Júnior, R. C., Medeiros, P. R. P., Costa, F. J. C. B., \& Andrade, E. L. (2003). Variação espacial da clorofila a na água do reservatório da UHE Xingó. In Anais do X Simpósio Brasileiro de Geografia Física Aplicada.

Silva, W. J. D., Nogueira, I. D. S., Melo-Magalhães, E. M. D., Benício, S. H. M., Pessoa, S. M., \& Menezes, M. (2018). Expansion of invasive Ceratium furcoides (Dinophyta) toward north-central Brazil: new records in tropical environments. Acta Limnologica Brasiliensia, (30).

Sistema de Referência Geocéntrico para las Américas - SIRGAS. (2000). Recuperado em 25 de novembro de 2018, de http://www.sirgas.org/pt/sirgas-realizations/sirgas2000/

Strickland, J. D. H., \& Parsons, T. R. (1960). A manual of sea water analysis. Bulletin - Fisheries Research Board of Canada, 125, 1-185.

Toledo Junior, A. D., Talarico, M., Chinez, S. J., \& Agudo, E. G. (1983). A aplicação de modelos simplificados para a avaliação do processo da eutrofização em lagos e reservatórios tropicais. In Anais do XII Congresso Brasileiro de Engenharia Sanitária e Ambiental. Camboriú: CETESB.

Tucci, A., \& Sant'Anna, C. L. (2003). Cylindrospermopsis raciborskii (Woloszynska) Seenayya \& Subba Raju (Cyanobacteria): weekly variation and relation with environmental factors in an eutrophic lake, São Paulo, SP, Brazil. Brazilian Journal of Botany, 26(1), 97-112. 
Tundisi, J. G., \& Tundisi, T. M. (2016). Limnologia (632 p.). São Paulo: Oficina de Textos.

\section{Contribuições dos autores:}

Thiago João Matias Silva - Contribuição ao manuscrito: Responsável pelo levantamento de dados secundários e tratamento dos dados, os quais fazem parte de sua dissertação de mestrado.

Nélia Henriques Callado - Contribuição ao manuscrito: Responsável pela supervisão e acompanhamento geral do trabalho, assim como da análise de dados com foco na qualidade das águas e correção geral do artigo.

Vladimir Caramori Borges de Souza - Contribuição ao manuscrito: Orientação metodológica da pesquisa, análise de dados, revisão e correção do artigo.

Maria Raphaella dos Santos Vasconcelos Contribuição ao manuscrito: Correções no texto em geral e, sobretudo no das cianobactérias, ajustando os parágrafos na cadência de ideias, os nomes científicos e tabelas. 